\title{
Hematologic Characteristics of Patients with Active Pulmonary, Extra-Pulmonary and Disseminated Tuberculosis: A Study of over Six Hundred Patients
}

\author{
Laith Alamlih", Mutaz Albakri², Wanis H. Ibrahim ${ }^{3 *}$, Aziz Khan', Fahmi Y. Khan1 \\ ${ }^{1}$ Department of Medicine, Hamad General Hospital, Doha, Qatar \\ ${ }^{2}$ Pulmonary Division, Department of Medicine, Hamad General Hospital, Doha, Qatar \\ ${ }^{3}$ Department of Medicine, Hamad General Hospital, Weill-Cornell Medicine, Doha, Qatar \\ ${ }^{4}$ Department of Internal Medicine, Uconn Health, Farmington, CT, USA \\ Email: Lalamlih@hamad.qa, Malbakri1@hamad.qa, ‘wanisian@yahoo.com, azizaku@gmail.com, Fakhanqal@gmail.com
}

How to cite this paper: Alamlih, L., Albakri, M., Ibrahim, W.H., Khan, A. and Khan, F.Y. (2020) Hematologic Characteristics of Patients with Active Pulmonary, Extra-Pulmonary and Disseminated Tuberculosis: A Study of over Six Hundred Patients. Journal of Tuberculosis Research, 8, 33-41.

https://doi.org/10.4236/jtr.2020.82004

Received: April 4, 2020

Accepted: May 15, 2020

Published: May 18, 2020

Copyright $\odot 2020$ by author(s) and Scientific Research Publishing Inc. This work is licensed under the Creative Commons Attribution International License (CC BY 4.0).

http://creativecommons.org/licenses/by/4.0/

(c) (i) Open Access

\begin{abstract}
Background: Many inflammatory cells, cytokines, acute phase reactants as well as platelets are recruited in the battle against the invading mycobacterium. As a result, alterations in the hematologic profile of infected patients are anticipated. Objectives: The primary objective was to investigate the various hematologic characteristics of patients with active tuberculosis. The secondary objective was to study the correlation between such hematologic characteristics and the type of tuberculosis including pulmonary, extra-pulmonary, and disseminated. Methods: This was a retrospective, descriptive study investigating the hematological findings in adult patients (aged 18 years or older) with active, bacteriologically-confirmed tuberculosis infection. Results: Among the 605 confirmed active tuberculosis cases, 465 (78.8\%) were pulmonary, 104 (17.6\%) extra-pulmonary, and 21 (3.6\%) disseminated type. The mean age at diagnosis was $33.4 \pm 11.4$ years and males constituted $80.2 \%$ of cases. Peripheral leukocytosis was observed in 177 (30.1\%) and leukopenia in 7 (1.2\%) (Pulmonary type of tuberculosis was significantly associated with leukocytosis $(P=0.000)$ ). Neutrophilia, lymphocytosis, monocytosis, eosinophilia, and basophilia were observed in $15.3 \%, 3.1 \%, 10.4 \%, 6.3 \%$ and $4.7 \%$ respectively. Thrombocytopenia and thrombocytosis were observed in $3.9 \%$ and $26.7 \%$ respectively. Anemia was observed in $44.8 \%$ of all cases with $4.4 \%$ had severe anemia and $60.3 \%$ had anemia of chronic diseases. Erythrocyte sedimentation rate was high in $77.2 \%$ of cases and $\geq 100 \mathrm{~mm} / \mathrm{hr}$ in $5 \%$. C-reactive protein was high in $93.4 \%$ and it exceeded $40 \mathrm{mg} / \mathrm{L}$ in $69.3 \%$. Conclusion: There is a wide range of variability in the leukocyte and differential leukocyte abnormalities observed in
\end{abstract}


patients with active tuberculosis. Leukocytosis can be seen in one-third of patients with pulmonary tuberculosis. Anemia of chronic diseases is the most common type of anemia observed in tuberculosis patients. Erythrocyte sedimentation rate and C-reactive protein are elevated in the majority of patients with active tuberculosis. Levels of the sedimentation rate can be useful indices to determine the extent of the disease.

\section{Keywords}

Tuberculosis, Anemia, Leukocytes, Blood Sedimentation, Platelet Count, C-Reactive Protein

\section{Introduction}

Tuberculosis (TB) remains a major global health problem. It is one of the top ten causes of death worldwide and the leading cause of death from a single infectious agent [1]. In the year 2010, an estimated ten million people fell ill with TB [1]. The diagnosis of TB remains a significant challenge despite the recent advent of molecular technologies. This diagnostic hurdle comes from the paucibacillary nature of the disease, the long time required to culture the bacteria, the low sensitivity of the new technologies, and the wide variety of clinical manifestations caused by the disease.

Inflammation is critical for TB pathogenesis. Many inflammatory cells are recruited in the battle against the invading Mycobacterium tuberculosis (MTB) bacilli including macrophages, monocytes, neutrophils, and primed T cells and $\mathrm{B}$ cells. Several pro- and anti-inflammatory cytokines, chemokines, and proteins are also produced by these cells with the most common outcome being lifetime control of the infection [2]. Besides these inflammatory cells, markers of platelet activity are also increased in plasma of patients with pulmonary TB compared with healthy control subjects. This platelet activity can alter the pro-inflammatory response and normalizes with anti-mycobacterial treatment [3] [4] [5]. Consequently, different studies have reported the presence of thrombocytosis in patients with TB. This increase in the platelet count has been correlated with the severity of TB and acute phase reactants [4] [6] [7]. Based on these facts, it is anticipated that TB infection can produce a range of alterations in the hematologic profiles of infected patients.

TB remains a common health problem in the state of Qatar with an incidence of 40/100,000 populations per year. About $97 \%$ of TB patients are expatriates (mostly from Asian countries with high TB prevalence). Qatar has a highly effective National TB Program with a case detection rate exceeding 70\% [8]. All medications, laboratory, and radiological investigations for the diagnosis of TB are provided free-of-charge to all patients. To the best of our knowledge, hematologic characteristics in a large cohort of subjects with various types of active TB have seldom been reported in the literature. 
The primary objective of this study was to investigate the various hematologic characteristics of patients with active TB. The secondary objective was to study the correlation between such hematologic characteristics and the type of TB including pulmonary, extra-pulmonary, and disseminated.

\section{Methods}

\section{Study settings and subjects}

This was a retrospective, descriptive study investigating the hematological findings in adult patients (aged 18 years or older) with active, bacteriologically-confirmed TB infection who were admitted to Hamad General Hospital (HGH) (a university-affiliated and the largest tertiary referral hospital) during the period from $1^{\text {st }}$ January 2010 till $31^{\text {st }}$ August 2016. Because of the anticipated effects of anti-tuberculous medications on different hematologic values, only results of hematologic tests at initial presentation and before the initiation of anti-tuberculous medications were included in the analysis.

\section{Study definitions}

Bacteriologically-confirmed TB case was defined in this study as a patient who received the diagnosis of active TB infection based on a positive acid-fast bacilli (AFB) smear in body fluids, and/or a positive MTB culture, and/or a positive MTB Polymerase Chain Reaction (PCR). The National Reference TB Laboratory in the State of Qatar performs a full range of TB work-up on any sample of suspected TB including MTB culture (using BACTEC MGIT 960 media-both solid and liquid media), PCR (GeneXpert MTB/RIF assay), fluorescence microscopy and Ziehl-Neelsen staining technique. Sputum for AFB is collected at HGH according to the Hamad Medical Corporation guidelines and the international standards [9].

Pulmonary TB was defined as TB that is confined to the lungs and diagnosed based on bacteriologically-positive sputum, Broncho-alveolar lavage (BAL), or lung biopsy. Extra-pulmonary TB was defined as an extra-pulmonary involvement in the absence of any evidence of lung infection and is bacteriologically confirmed by a positive biopsy or fluid analysis. Disseminated TB was defined as concomitant pulmonary and extra-pulmonary involvement.

\section{Data collection}

Two investigators (LA \& MA) independently performed an extensive review of the electronic medical records related to the enrolled patients. Using a standardized electronic form, each of the two investigators independently collected data regarding the demographic characteristics of the study subjects, the type of $\mathrm{TB}$, the bacteriologic results, and the various hematologic parameters at the time of TB diagnosis. For quality assurance, three senior investigators (WI, AK \& FK) further reviewed the collected data to confirm the accuracy of the information obtained.

\section{Statistical analysis}

Qualitative and quantitative data values were expressed as frequency along with percentage and mean \pm standard deviation with the median. Descriptive 
statistics were used to summarize demographic and all other clinical characteristics of the participants. Associations between hematologic parameters and the type of TB were assessed using the Chi-square test. A two-sided $\mathrm{P}<0.05$ was considered to be statistically significant. All Statistical analyses were performed using Statistical Packages SPSS-21 (SPSS Inc., Chicago, IL, USA).

\section{Results}

Among the 605 confirmed active TB cases, 465 (78.8\%) were pulmonary, 104 (17.6\%) extra-pulmonary and 21 (3.6\%) disseminated type. The mean age at diagnosis was $33.4 \pm 11.4$ years. Males constituted $80.2 \%$ and females $19.8 \%$ of all cases. The majority of patients were from the Indian subcontinent (66.1\%) while Africans and Filipinos constituted $15.6 \%$ and $14.3 \%$ respectively. Only $2.9 \%$ of patients were Qatari nationals. Peripheral leukocytosis was observed in 177 (30.1\%) and leukopenia in 7 (1.2\%) (Pulmonary type of TB was significantly associated with leukocytosis $(\mathrm{P}=0.000)$ ). Neutrophilia, lymphocytosis, monocytosis, eosinophilia, and basophilia were observed in $15.3 \%, 3.1 \%, 10.4 \%, 6.3 \%$ and $4.7 \%$ respectively. Thrombocytopenia and thrombocytosis were observed in $3.9 \%$ and $26.7 \%$ respectively (Table 1 and Table 2). Anemia was observed in $44.8 \%$ of all $\mathrm{TB}$ cases and severe anemia (defined as $\mathrm{Hb}<8 \mathrm{~g} / \mathrm{dl}$ ) in $4.4 \%$ of cases. Anemia of chronic diseases constituted the majority of all types of anemia (60.3\%) observed in TB patients (Table 3). Erythrocyte sedimentation rate (ESR) was high in $77.2 \%$ of cases and C-reactive protein (CRP) in $93.4 \%$. About $5 \%$ of cases had ESR of $100 \mathrm{~mm} / \mathrm{hr}$ or higher and 69.3\% had CRP above $40 \mathrm{mg} / \mathrm{L}$ (Table 4).

Table 1. Complete blood count.

\begin{tabular}{|c|c|c|c|c|c|}
\hline & All TB cases & Pulmonary & Extrapulmonary & Disseminated & P-value \\
\hline \multicolumn{6}{|l|}{$\mathrm{WBC}(\mathrm{n}=589)$} \\
\hline$\times 10^{3} / \mathrm{uL}$ & $\mathrm{N}(\%)$ & $\mathrm{N}(\%)$ & $\mathrm{N}(\%)$ & $\mathrm{N}(\%)$ & \multirow{4}{*}{0.000} \\
\hline Normal $(4-10)$ & $405(68.8 \%)$ & $294(63.9 \%)$ & $93(89.4 \%)$ & $18(85.7 \%)$ & \\
\hline Low $<4$ & $7(1.2 \%)$ & $6(1.3 \%)$ & $1(1 \%)$ & $0(0 \%)$ & \\
\hline High $>10$ & $177(30 \%)$ & $160(34.8 \%)$ & $10(9.6 \%)$ & $3(14.3 \%)$ & \\
\hline \multicolumn{6}{|l|}{ Presence of anemia } \\
\hline Anemia present & $271(44.8 \%)$ & $217(46.7 \%)$ & $41(39.4 \%)$ & $11(52.4 \%)$ & \multirow{2}{*}{0.333} \\
\hline Anemia absent & $334(55.2 \%)$ & $248(53.3 \%)$ & $63(60.6 \%)$ & $10(47.6 \%)$ & \\
\hline \multicolumn{6}{|l|}{ Hematocrit level } \\
\hline Low $\mathrm{HCT}<40 \%$ & $270(45.9 \%)$ & $215(46.7 \%)$ & $40(38.5 \%)$ & $13(61.9 \%)$ & \multirow{3}{*}{0.289} \\
\hline Normal HCT $40 \%$ - 50\% & $300(50.9 \%)$ & $230(50 \%)$ & $60(57.7 \%)$ & $8(38.1 \%)$ & \\
\hline High HCT $>50 \%$ & $19(3.2 \%)$ & $15(3.3 \%)$ & $4(3.8 \%)$ & $0(0 \%)$ & \\
\hline \multicolumn{6}{|l|}{ Platelet count $\left(\times 10^{3} / \mathrm{uL}\right)$} \\
\hline Normal platelet count $(150-400)$ & $407(69.3 \%)$ & $325(71 \%)$ & $67(64.4 \%)$ & $14(66.7 \%)$ & \multirow{3}{*}{0.343} \\
\hline Low platelet count $<150$ & $23(3.9 \%)$ & $20(4.4 \%)$ & $2(1.9 \%)$ & $1(4.8 \%)$ & \\
\hline High platelet count $>400$ & $157(26.7 \%)$ & $113(24.6 \%)$ & $35(33.7 \%)$ & $6(28.5 \%)$ & \\
\hline
\end{tabular}




\section{Continued}

\begin{tabular}{ccccc} 
Mean Platelet Volume (MPV) (fL) & & & & \\
Normal MPV 7.4 - 10.4 & $293(68.6 \%)$ & $226(68.7 \%)$ & $53(68 \%)$ & $14(73.7 \%)$ \\
Low MPV < 7.4 & $110(25.8 \%)$ & $86(26.1 \%)$ & $20(25.6 \%)$ & $3(15.8 \%)$ \\
High MPV > 10.4 & $24(5.6 \%)$ & $17(5.2 \%)$ & $5(6.4 \%)$ & $2(10.5 \%)$ \\
\hline
\end{tabular}

Table 2. Differential leukocyte count.

\begin{tabular}{|c|c|c|c|c|c|}
\hline Differential count & All TB cases & Pulmonary & Extrapulmonary & Disseminated & $P$-value \\
\hline Neutrophil count $\left(\times 10^{3} / \mathrm{uL}\right)$ & & & $\mathrm{N}(\%)$ & & \multirow{4}{*}{0.001} \\
\hline Normal 2 - 7 & $390(83.9 \%)$ & $281(80.3 \%)$ & $94(98.9 \%)$ & $15(83.3 \%)$ & \\
\hline Low $<2$ & $4(0.9 \%)$ & $4(1.1 \%)$ & $0(0 \%)$ & $0(0 \%)$ & \\
\hline High $>7$ & $71(15.3 \%)$ & $65(18.6 \%)$ & $1(1.1 \%)$ & $3(16.7 \%)$ & \\
\hline Lymphocyte count $\left(\times 10^{3} / \mathrm{uL}\right)$ & & & $\mathrm{N}(\%)$ & & \multirow{4}{*}{0.050} \\
\hline Normal 1 - 3 & $429(72.8 \%)$ & $344(74.8 \%)$ & $69(66.3 \%)$ & $12(57.1 \%)$ & \\
\hline Low $<3$ & $142(24.1 \%)$ & $100(21.7 \%)$ & $33(31.7 \%)$ & $9(42.9 \%)$ & \\
\hline High $>3$ & $18(3.1 \%)$ & $16(3.5 \%)$ & $2(2 \%)$ & $0(0 \%)$ & \\
\hline Monocyte count $\left(\times 10^{3} / \mathrm{uL}\right)$ & & & $\mathrm{N}(\%)$ & & \multirow{4}{*}{0.449} \\
\hline Normal $0.2-1.0$ & $519(88.1 \%)$ & $402(87.4 \%)$ & $94(90.3 \%)$ & $21(100 \%)$ & \\
\hline Low $<0.19$ & $9(1.5 \%)$ & $8(1.7 \%)$ & $1(1 \%)$ & $0(0 \%)$ & \\
\hline High $>1.1$ & $6(10.4 \%)$ & $50(10.9 \%)$ & $9(8.7)$ & $0(0 \%)$ & \\
\hline Eosinophil count $\left(\times 10^{3} / \mathrm{uL}\right)$ & & & $\mathrm{N}(\%)$ & & \multirow{3}{*}{0.795} \\
\hline Normal $0.0-0.5$ & $552(39.7 \%)$ & $432(93.9 \%)$ & $96(92.3 \%)$ & $20(95.2 \%)$ & \\
\hline High $>0.5$ & $37(6.3 \%)$ & $28(6.1 \%)$ & $8(7.7 \%)$ & $1(4.8 \%)$ & \\
\hline Basophil count $\left(\times 10^{3} / \mathrm{uL}\right)$ & & & $\mathrm{N}(\%)$ & & \multirow{3}{*}{0.837} \\
\hline Normal $0.02-0.10$ & $225(95.3 \%)$ & $157(95.2 \%)$ & $54(96.4 \%)$ & $13(92.9 \%)$ & \\
\hline High $>0.10$ & $11(4.7 \%)$ & $8(4.8 \%)$ & $2(3.6 \%)$ & $1(7.1 \%)$ & \\
\hline
\end{tabular}

Table 3. Anemia severity and type.

\begin{tabular}{|c|c|c|c|c|c|}
\hline \multicolumn{6}{|c|}{ Anemia severity } \\
\hline & All cases & Pulmonary TB & Extrapulmonary $\mathrm{TB}$ & Disseminated & P-value \\
\hline $\mathrm{gm} / \mathrm{dl}$ & $\mathrm{N}(\%)$ & $\mathrm{N}(\%)$ & $\mathrm{N}(\%)$ & & \\
\hline Mild anemia (Hb 11 - 12.9) & $179(66.1 \%)$ & $142(65.4 \%)$ & $30(73.1 \%)$ & $6(54.5 \%)$ & \\
\hline Moderate anemia (Hb 8 - 10.9) & $80(29.5 \%)$ & $66(30.4 \%)$ & $9(22 \%)$ & $5(45.5 \%)$ & 0.584 \\
\hline Severe anemia $(\mathrm{Hb}<8)$ & $12(4.4 \%)$ & $9(4.2 \%)$ & $2(4.9 \%)$ & $0(0 \%)$ & \\
\hline \multicolumn{6}{|c|}{ Anemia type } \\
\hline Anemia type & $\mathrm{N}(\%)$ & & & & \\
\hline Iron deficiency & $21(17.4 \%)$ & & & & \\
\hline Anemia of chronic diseases & $73(60.3 \%)$ & & & & \\
\hline $\begin{array}{l}\text { Mixed iron deficiency and } \\
\text { anemia of chronic disease }\end{array}$ & $25(20.7 \%)$ & & & & \\
\hline Other types of anemia & $2(1.7 \%)$ & & & & \\
\hline
\end{tabular}


Table 4. ESR and CRP.

\begin{tabular}{cccccc}
\hline & All TB cases & Pulmonary & Extrapulmonary & Disseminated & P-value \\
\hline ESR $(\mathrm{mm} / \mathrm{hr})$ & & & $\mathrm{N}(\%)$ & & \\
Normal 0 - 30 & $84(22.8 \%)$ & $69(24 \%)$ & $10(15.2 \%)$ & $3(23.1 \%)$ & \\
High 31 - 99 & $266(72.1 \%)$ & $204(71.1 \%)$ & $55(83.3 \%)$ & $7(53.8 \%)$ & 0.008 \\
Very high > 99 & $19(5.1 \%)$ & $14(4.9 \%)$ & $1(1.5 \%)$ & $3(23.1 \%)$ & \\
CRP (mg/L) & & & $\mathrm{N}(\%)$ & & \\
Normal 0 - 5 & $19(6.6 \%)$ & $14(6.6 \%)$ & $2(3.3 \%)$ & $3(18.8 \%)$ & \\
High 6 - 40 & $70(24.1 \%)$ & $57(26.9 \%)$ & $10(16.4 \%)$ & $3(18.8 \%)$ & 0.078 \\
Very high > 40 & $201(69.3 \%)$ & $141(66.5 \%)$ & $49(80.3 \%)$ & $10(62.5 \%)$ & \\
\hline
\end{tabular}

\section{Discussion}

Some of the disease manifestations in the human body such as fever and cachexia along with alterations in the hematologic parameters are attributed to cytokine excess [10] [11]. Sedimentation of red cells is affected by forces both for and against sedimentation and the ESR is one of the acute-phase reactants that react to acute conditions in the body, such as infection, burns, surgery, or trauma [12]. The plasma concentration CRP increases during inflammatory states, a characteristic that has long been employed for clinical purposes. Its rapid increase in synthesis within hours after tissue injury or infection suggests that it contributes to host defense and that it is a part of the innate immune response [13]. The current study has shown that TB, in the State of Qatar, is a predominantly disease of young Asian men. This finding has also been demonstrated in previous studies by Ibrahim et al. and is expected in a country that relies heavily on the labor force from Asia for its economic and industrial projects [14] [15]. We have also demonstrated variable abnormalities in the leukocyte and differential leukocyte count with the most common being leukocytosis (30.1\%), lymphopenia (24.1\%), and neutrophilia (15.3\%). Variability in leukocyte count seems a common finding in TB and has been previously reported in multiple studies. Bozoky et al. [16] in 1997 investigated the hematologic abnormalities in 380 patients with pulmonary TB. Leukocytosis with neutrophilia occurred in $18 \%$. Leucopenia with neutropenia and lymphopenia was observed in $16 \%$ of patients with very severe clinical TB. Singh KJ et al. [17] prospectively examined the hematologic manifestations in 32 patients with disseminated/miliary TB and 23 patients with pulmonary TB. Hematologic abnormalities of the white blood cells included leucopenia (disseminated/miliary $25 \%$, pulmonary TB $0 \%$ ) with neutropenia (disseminated/miliary $22 \%$, PTB 0\%). Lymphocytopenia, monocytopenia, leukocytosis, neutrophilia, lymphocytosis, and monocytosis were also reported. In the current study, we also demonstrated a $44.8 \%$ prevalence of anemia and $4.4 \%$ of severe anemia. Anemia of chronic disease accounted for $60.3 \%$ of anemia cases. In a study of the prevalence and characteristics of anemia among 880 patients with $\mathrm{TB}$, Lee et al. [18] reported a prevalence of $31.9 \%$ with a hemoglobin concentra- 
tion of less than $10 \mathrm{~g} / \mathrm{dL}$ in $5 \%$ of cases. Normocytic and normochromic type of anemia was the most common among these patients. Similar prevalence has also been reported in other studies [16]. Nevertheless, few other studies reported higher anemia prevalence among TB patients. In the prospective study by Singh KJ et al. [17], normocytic normochromic anemia was observed in $84 \%$ of the disseminated/miliary cases and $86 \%$ of the pulmonary TB cases. More recent evidence supports the role of platelets in the host inflammatory and immune responses. Furthermore, recent studies have also suggested the importance of mean platelet volume (MPV) as an inflammation marker in some chronic inflammatory disorders, such as rheumatoid arthritis, ulcerative colitis, and psoriasis [19] [20]. Lee et al. [20] suggested that MVP can be an easy and fast marker to determine the disease activity in patients with TB and MVP changes according to the changes in CRP and age in TB patients. In the present study, the prevalence of thrombocytosis, thrombocytopenia, and high MPV were 26.7\%, 3.9\%, and 5.6\% respectively. One of the striking findings in our study is the significant associations between total leukocyte count, ESR level, and the type of TB. Leukocytosis was significantly associated with pulmonary TB and ESR level above $99 \mathrm{~mm} / \mathrm{hr}$ was significantly associated with disseminated TB. A point of strength in this study is that it documented the prevalence of various hematologic abnormalities in a large cohort of TB patients. The study was conducted in a country with a highly effective National TB Program and one National TB Reference Laboratory that performs a full range of laboratory diagnosis. Furthermore, this study has documented the association between the hematologic findings and the various types of TB which was seldom reported in previous studies. Nevertheless, this study has potential limitations. Among the most important limitation is the retrospective nature of the study and its inherited bias. Despite the efforts made to search for and document accurate information by two independent investigators, missing information was a major encounter. Furthermore, due to the low incidence of Human immunodeficiency viral (HIV) infection in this country and the high TB incidence, HIV testing is not routinely conducted for patients with newly diagnosed TB unless there are other signs and symptoms. This, in turn, did not permit the comparison of the hematologic profile of HIV-infected and HIV-negative patients. Nevertheless, careful search in medical records and follow up notes did not point to the presence of HIV infection in any of the study subjects.

\section{Conclusion}

There is a wide range of variability in the leukocyte and differential leukocyte abnormalities observed in patients with active TB. Leukocytosis can be seen in one-third of patients with pulmonary TB. Anemia of chronic diseases is the most common type of anemia observed in TB patients. ESR and CRP are elevated in the majority of patients with active TB. Levels of ESR can be useful indices to determine the extent of the disease. 


\section{Funding}

This research was funded by the Medical Research Council of Hamad Medical Corporation.

\section{Ethical Approval}

The study was approved by the ethical committee of the Medical Research Center of Hamad Medical Corporation (Approval No. 16400/16).

\section{Conflicts of Interest}

The authors declare no conflicts of interest regarding the publication of this paper.

\section{References}

[1] World Health Organization. Global Tuberculosis Report 2019. https://apps.who.int/iris/bitstream/handle/10665/329368/9789241565714-eng.pdf?ua=1

[2] Flynn, J.L., Chan, J. and Lin, P.L. (2011) Macrophages and Control of Granulomatous Inflammation in Tuberculosis. Mucosal Immunology, 4, 271-278.

https://doi.org/10.1038/mi.2011.14

[3] Fox, K.A., Kirwan, D.E., Whittington, A.M., Krishnan, N., Robertson, B., Gilman, R., et al. (2018) Platelets Regulate Inflammation in Tuberculosis. American Journal of Respiratory and Critical Care Medicine, 198, 245-255. https://doi.org/10.1164/rccm.201710-2102OC

[4] Şahin, F., Yazar, E. and Yıldız, P. (2012) Prominent Features of Platelet Count, Plateletcrit, Mean Platelet Volume, and Platelet Distribution Width in Pulmonary Tuberculosis. Multidisciplinary Respiratory Medicine, 7, 1-7. https://doi.org/10.1186/2049-6958-7-38

[5] Mirsaeidi, M., Peyrani, P., Aliberti, S., Filardo, G., Bordon, J., Blasi, F., et al. (2010) Thrombocytopenia and Thrombocytosis at Time of Hospitalization Predict Mortality in Patients with Community-Acquired Pneumonia. Chest, 137, 416-420. https://doi.org/10.1378/chest.09-0998

[6] Tozkoparan, E., Deniz, O., Ucar, E., Bilgic, H. and Ekiz, K. (2007) Changes in Platelet Count and Indices in Pulmonary Tuberculosis. Clinical Chemistry and Laboratory Medicine, 45, 1009-1013. https://doi.org/10.1515/CCLM.2007.194

[7] Unsal, E., Aksaray, S., Köksal, D. and Sipit, T. (2005) Potential Role of Interleukin 6 in Reactive Thrombocytosis and Acute Phase Response in Pulmonary Tuberculosis. Postgraduate Medical Journal, 81, 604-607. https://doi.org/10.1136/pgmj.2004.030544

[8] AL-Suwaidi, Z. (2015) Tuberculosis in Qatar. International Journal of Mycobacteriology, 4, 124. https://doi.org/10.1016/j.ijmyco.2014.10.052

[9] Hamad Medical Corporation (2015) Microbiology Specimen Guidelines-SOP. https://itawasol.hamad.qa/EN/How\%20We\%20Work/Clinical_Services/Laboratory/ Documents/Microbiology\%20Specimen\%20Guidelines\%202013.pdf\#search=microb

[10] Andus, T., Bauer, J. and Gerok, E. (1991) Effects of Cytokines on the Liver. Hepatology, 13, 364-375. https://doi.org/10.1002/hep.1840130226

[11] Oliva, V.M., Cezário, G.A., Cocato, R.A. and Marcondes-Machado, J. (2008) Pulmonary Tuberculosis: Hematology, Serum Biochemistry, and the Relation with the 
Disease Duration. Journal of Venomous Animals and Toxins including Tropical Diseases, 14, 71-81. https://doi.org/10.1590/S1678-91992008000100006

[12] Hameed, A. and Waqas, S. (2006) Physiological Basis and Clinical Utility of Erythrocyte Sedimentation Rate. Pakistan Journal of Medical Sciences, 22, 214-218.

[13] Black, S., Kushner, I. and Samols, D. (2004) C-Reactive Protein. Journal of Biological Chemistry, 279, 48487-48490. https://doi.org/10.1074/jbc.R400025200

[14] Ibrahim, W.H., Alousi, F.H., Al-Khal, A., Bener, A., AlSalman, A., Aamer, A., et al. (2016) Diagnostic Delay among Adults with Pulmonary Tuberculosis in a High Gross Domestic Product per Capita Country: Reasons and Magnitude of the Problem. International Journal of Preventive Medicine, 7, 116. https://doi.org/10.4103/2008-7802.193091

[15] Ibrahim, W.H., Ghadban, W., Khinji, A., Yasin, R., Soub, H., Al-Khal, A., et al. (2005) Does Pleural Tuberculosis Disease Pattern Differ among Developed and Developing Countries? Respiratory Medicine, 99, 1038-1045.

https://doi.org/10.1016/j.rmed.2004.12.012

[16] Bozóky, G., Ruby, E., Góhér, I., Tóth, J. and Mohos, A. (1997) Hematologic Abnormalities in Pulmonary Tuberculosis. Orvosi Hetilap, 138, 1053-1056.

[17] Singh, K.J., Ahluwalia, G., Sharma, S.K., Saxena, R., Chaudhary, V.P. and Anant, M. (2001) Significance of Hematological Manifestations in Patients with Tuberculosis. Journal of the Association of Physicians of India, 49, 788-794.

[18] Lee, S.W., Kang, Y.A., Yoon, Y.S., Um, S.W., Lee, S.M., Yoo, C.G., et al. (2006) The Prevalence and Evolution of Anemia Associated with Tuberculosis. Journal of Korean Medical Science, 21, 1028-1032. https://doi.org/10.3346/jkms.2006.21.6.1028

[19] Gasparyan, A.Y., Ayvazyan, L., Mikhailidis, D.P. and Kitas, G.D. (2011) Mean Platelet Volume: A Link between Thrombosis and Inflammation? Current Pharmaceutical Design, 17, 47-58. https://doi.org/10.2174/138161211795049804

[20] Lee, M.Y., Kim, Y.J., Lee, H.J., Cho, S.Y. and Park, T.S. (2016) Mean Platelet Volume in Mycobacterium Tuberculosis Infection. BioMed Research International, 2016, Article ID: 7508763. https://doi.org/10.1155/2016/7508763 